\title{
A EDUCAC̣ÃO DA INFÂNCIA: ENTRE A FAMÍLIA, A ESCOLA E A MEDICINA
}

\section{Heloísa Helena Pimenta Rocha*}

RESUMO: Este artigo examina comunicações apresentadas no II Congresso de Higiene Escolar e Pedagogia Fisiológica, realizado em Paris, em 1905, como fruto da iniciativa da Liga dos Médicos e das Famílias para a Higiene Escolar. Elegendo as comunicações que abordam questões ligadas à institucionalização da inspeção médica das escolas e aos dispositivos de registro dos dados obtidos por meio dos exames individuais dos alunos, procura-se flagrar as representações sobre a infância e sua educação produzidas no campo da higiene escolar, num momento marcado por intensas transformações sociais, importantes reformas voltadas para a universalização da escola primária, difusão de ideais de renovação e modernização pedagógica, bem como pela significativa ampliação das preocupações com a infância, sua proteção e sua educação. A análise das comunicações apresentadas nesse fórum põe em cena as disputas que marcaram o projeto de constituição de uma pedagogia científica calcada no conhecimento das leis que regiam o desenvolvimento da criança.

Palavras-chave: Infância; Higiene Escolar; Pedagogia.

\section{CHILDHOOD EDUCATION: AMONG FAMILY, SCHOOL AND MEDICINE}

ABSTRACT: This article is aimed at examining papers presented on the 2nd Congress of School Hygiene and Physiological Education held in Paris in 1905, as a result of the initiative of the Guild of Physicians and Families for School Hygiene. We aim at verifying the representations about childhood and education produced on the field of school hygiene in a period marked by intense social transformations, important reforms focused on the universalization of the elementary school, diffusion of ideals for the pedagogical renovation and modernization, as well as for the meaningful growth of concerns for childhood and children's protection and education. Therefore, we have selected papers that approach issues linked to the institutionalization of medical inspection of schools, and mechanisms of data collection obtained by means of individual students examination. The analysis of the papers presented in this forum highlights disputes that determined the project's constitution of a scientific pedagogy based on the knowledge of the laws that ruled child's development.

Keywords: Childhood; School Hygiene; Pedagogy.

\footnotetext{
* Doutora em História da Educação e Historiografia pela Universidade de São Paulo (USP), Pós-doutora pela Universidad de Buenos Aires; Professora na Faculdade de Educação da Universidade Estadual de Campinas (UNICAMP); Coordenadora do Grupo de Pesquisa Memória, História e Educação e Membro do Comitê Gestor do Centro de Memória da Educação da Faculdade de Educação da Universidade Estadual de Campinas (UNICAMP); Bolsista de produtividade em pesquisa do Conselho Nacional de Desenvolvimento Científico e Tecnológico (CNPq).E-mail: heloisah@unicamp.br
} 
A realização de congressos nacionais e internacionais de higiene escolar constituiu-se em uma das dimensões da difusão do higienismo, movimento internacional que se consolidou entre a segunda metade do século XIX e o início do século XX, em um contexto marcado por intensas transformações sociais, importantes reformas educativas ligadas à expansão da escolarização, pela difusão dos ideais de renovação e modernização pedagógica e, ainda, pela significativa ampliação das preocupações sobre a infância, sua proteção e sua educação. Articulada a um conjunto de iniciativas de variados matizes, a promoção desses eventos, os quais contaram com a participação de significativo número de representantes de diferentes países, tinha como um dos seus objetivos interferir sobre a configuração dos sistemas educativos (VIÑAO FRAGO; MARTINEZ, 2000; MARTINEZ, 2006).

Tais propósitos se justificam quando se tem em conta que os médicos higienistas, no afã de debelar as epidemias, combater a mortalidade e produzir novos modos de viver em sociedade, consideraram a escola como objeto privilegiado de intervenção, dedicando-se ao estudo dos tempos e espaços da escolarização, dos métodos e procedimentos de ensino, bem como da constituição física e intelectual dos alunos. Como destacam Viñao Frago e Martinez, "a partir de presupuestos higiénicos, se pretendía regular la vida de los individuos, de las familias y de los grupos sociales en toda su amplitud, aunque la escuela y la familia constituyeran, desde su inicio, dos de los lugares privilegiados de intervención del higienismo" (VIÑAO FRAGO; MARTÍNEZ, 2000, p. 7).

Nesse sentido, a confluência entre a medicina, a higiene e a educação escolar mostrou-se inevitável, segundo Viñao Frago, já que a escola se apresentava como espaço social por meio do qual era possível tanto garantir a atenção médico-higiênica à infância, quanto intervir sobre as famílias, reorientando suas práticas cotidianas de cuidado e educação das crianças. Em síntese, "la medicalización de la infancia se daba la mano con su escolarización. Y esta última con la higienización de la escuela" (VIÑAO FRAGO, 2000).

Como assinala Kuhlmann Jr. (2005; 2007), os congressos profissionais, que se tornam frequentes a partir de 1870, elegendo como objeto de discussão as mais diferentes temáticas, entre elas a educação, representaram importante impulso à difusão internacional de concepções de educação, assim como de instituições educativas. Reunindo 
representantes de diferentes países, esses eventos puseram em discussão um amplo leque de questões articuladas em torno dos propósitos de legitimação de modelos e formas de integração ao círculo das nações consideradas civilizadas. Com base no exame da documentação do Congresso Internacional de Ensino, realizado em Bruxelas, em 1880, o autor sugere que a materialização das ideias debatidas no âmbito de reuniões dessa natureza, em políticas e instituições, possibilita compreender um fazer político que se situa em instâncias não necessariamente subordinadas às instituições políticas do Estado.

No que se refere à produção e à circulação de representações sobre a infância e ao papel dos médicos na formulação de propostas voltadas para a sua educação, os congressos de higiene escolar podem oferecer importantes indícios, uma vez que permitem compreender as questões em pauta na agenda internacional, bem como os diferentes movimentos por meio dos quais se buscou apresentar como legítima e necessária a intervenção dos médicos sobre a instituição escolar e as crianças. $\mathrm{Na}$ análise desses congressos, cabe lembrar que eles eram, em geral, organizados por sociedades ou associações de médicos interessados nesse campo, como assinala Bañuelos $(2000)^{1}$. A sua realização resultou, também, da iniciativa de ligas e sociedades compostas por médicos, políticos reformistas e profissionais de classe média, entre as quais a autora destaca a Ligue Belgue d'Enseignement e a Ligue des Médecins et de Familles pour l'Hygiène Scolaire, fundada na França, em 1902, sob a direção de Albert Mathieu (BAÑUELOS, 2000).

Este artigo examina comunicações apresentadas no II Congresso de Higiene Escolar e Pedagogia Fisiológica, realizado em Paris, em 1905, como fruto da iniciativa da Liga dos Médicos e das Famílias para a Higiene Escolar (Ligue des Médecins et de Familles pour l'Hygiène Scolaire). Elegendo as comunicações que enfocam as temáticas ligadas à institucionalização da inspeção médica da escola e aos dispositivos de registro dos dados obtidos por meio dos exames individuais dos alunos, procura-se flagrar as representações sobre a infância e sua educação produzidas no campo da higiene escolar, bem como as disputas em torno da constituição de uma pedagogia científica calcada no conhecimento das leis que regiam o desenvolvimento da criança. 


\section{A higiene escolar e o imperativo de renovação pedagógica}

Uma das características do movimento de reforma da bigiene escolar e de renovação da pedagogia que distingue nossa época, é que ele se produz ao mesmo tempo em todos os povos civilizados. (MATHIEU, 1906, p. 6-7)

Presidida por Ernest Lavisse, membro da Academia Francesa e diretor da Escola Normal Superior, e por Landouzy, membro da Academia de Medicina, a sessão de abertura do congresso, realizada no anfiteatro da Faculdade de Medicina de Paris, foi marcada pelos discursos de algumas autoridades francesas e de alguns dos nomes de destaque na discussão das temáticas privilegiadas pelo evento ${ }^{2}$. Na organização dada à mesa, procurava-se, muito provavelmente, dar visibilidade à dimensão internacional que assumiam as questões em pauta e, ao mesmo tempo, garantir a legitimidade da iniciativa entre os próprios franceses. Assim, além do presidente da liga francesa, Albert Mathieu, responsável pela organização do congresso, foram convidados a tomar a palavra dois delegados estrangeiros e quatro autoridades francesas: Stocker, da Sociedade Suíça de Higiene Escolar e Unia Stein Parve, da Sociedade Holandesa para a Simplificação e Aprimoramento dos Exames e dos Programas. Do lado francês, pronunciaram-se, além de Mathieu e Butte, da Sociedade de Médicos-Inspetores da cidade de Paris, o presidente da sessão, Ernest Lavisse, e Jean-Charles Roux, secretário geral do congresso.

Em seus discursos, os delegados estrangeiros procuraram demonstrar sua satisfação pela participação no congresso, a qual se configurava uma oportunidade privilegiada para conhecer os resultados dos trabalhos que vinham sendo desenvolvidos na França ${ }^{3}$. O interesse por conhecer de perto a experiência francesa se justificava, segundo o representante suíço, tanto pelo pioneirismo daquele país nos mais diferentes campos da ciência quanto pelo entusiasmo que os franceses demonstravam em relação às questões ligadas à higiene escolar. Entusiasmo esse que se expressava na aprovação, havia mais de duas décadas, de dispositivos legais voltados para a higiene das escolas; na atuação da liga, no sentido de fazer cumprir tais exigências legais, garantindo a institucionalização da vigilância médica das escolas e de cada criança individualmente; e, ainda, nas conferências proferidas pelos estudiosos 
franceses nos eventos sobre a temática, realizados nos últimos anos, tanto na França quanto em outros países europeus ${ }^{4}$.

No caso do representante da associação holandesa, as expectativas mostravam-se ainda maiores, dado o estado incipiente da higiene escolar nos Países Baixos. Em suas palavras, o delegado expressava o desejo de ver implementado, em seu país, um serviço de higiene escolar organizado pelo Estado, já que, segundo destacava, ninguém mais ignorava a necessidade de que a criança fosse "colocada em um ambiente salubre e agradável, onde o ar e a luz circulem abundantemente" (PARVE, 1906).

Por seu lado, os discursos dos franceses caracterizavam-se pelas preocupações em ampliar a legitimidade das suas iniciativas no campo da higiene escolar. Nesse sentido, as análises do secretário do congresso, ao mesmo tempo em que ressaltavam a participação dos representantes estrangeiros, davam significativo destaque à pequena adesão das famílias francesas às iniciativas da liga, dado esse que poderia ser interpretado como evidência da pouca disponibilidade dos pais para trabalhar com os médicos, da extraordinária indiferença ou negligência das famílias ou, simplesmente, como indício de que a entidade era ainda insuficientemente conhecida, necessitando, portanto, de um trabalho mais amplo de publicidade.

As análises de Bañuelos sobre o primeiro congresso realizado pela liga, em Paris, no ano de 1903, considerado pela autora como um momento significativo na configuração do campo da higiene escolar, evidenciam que esse evento tivera como objetivo central conquistar "las adhesiones de los padres de familia para conseguir de las esferas oficiales mejoras higienicas de la escuela y su traducción más concreta, la asentación de la Inspección Médico-Escolar" (BAÑUELOS, 2000, p. 80). Em suas relações com os aspectos evidenciados por Jean-Charles Roux, na leitura dos dados do segundo congresso, tais objetivos podem ser reveladores dos conflitos que acompanharam o processo por meio do qual os médicos buscaram se impor como única voz autorizada em relação aos cuidados com a infância, bem como das resistências das famílias e dos professores a iniciativas que tinham como propósito a legitimação dos conhecimentos médicos sobre as crianças e sua educação ${ }^{5}$.

Bastante reveladora quanto a essas questões é a conferência proferida por Ernest Lavisse, na sessão de abertura do congresso. 
Referindo-se ao nome dado à entidade, que deveria reunir médicos e pais em torno da discussão das questões ligadas à higiene escolar, o conferencista destaca a adequação da escolha: "O nome que vocês deram à sua Sociedade é bem escolhido. Vocês a denominaram 'liga'. Liga dá a idéia de uma ação vigorosa, bélica. Será necessário, com efeito, um grande vigor na guerra que vocês declararam contra os maus hábitos que perduram no regime de educação" (LAVISSE, 1906, p. 15). Nessa guerra, os alvos contra os quais deveriam se voltar os membros da liga seriam os hábitos adotados pelas famílias e os modos de educação praticados nas escolas.

Quanto às famílias, Lavisse demonstra sua preocupação com o que considerava a desoladora inércia dos pais, manifestando o desejo de ver ampliada sua participação na liga. Citando exemplos colhidos em sua experiência durante o período em que fora professor do liceu, procura demonstrar a oposição existente entre os interesses das mães e os objetivos da higiene escolar: "a ambição das mães é inimiga da higiene escolar” (LAVISSE, 1906). Tal conclusão fora extraída, segundo ele, da observação das atitudes das mães que acorriam à escola preocupadas unicamente em evitar que seus filhos fossem submetidos a castigos e em assegurar que eles estivessem entre os primeiros da classe.

No que se refere ao papel exercido pela escola na educação das crianças, suas críticas dirigem-se ao regime escolar, o qual se constituía, segundo ele, em uma "violência contra a natureza" da criança (LAVISSE, 1906). Na demonstração da sua posição, o conferencista lança mão, num primeiro momento, das lembranças da sua experiência escolar como aluno de instituições onde as práticas de asseio corporal, como o banho dos pés ou do corpo inteiro, sequer eram previstas e cujo código de conduta considerava as conversas na classe ou durante as refeições como atitudes reprováveis, o ato de fumar, como um verdadeiro crime, entretanto, não tratava como um delito a sujeira. Nem só o descaso quanto ao asseio corporal, entretanto, evidenciava a violência a que se refere Lavisse. Segundo ele, todo o regime escolar testemunhava a sua afirmação, bastando lembrar os espaços destinados ao estudo, as classes, os dormitórios mal-arejados e iluminados, as reduzidas quadras reservadas aos jogos, o sedentarismo e a imobilidade das crianças.

As críticas do conferencista quanto ao regime escolar não se limitavam à escola do passado. Em sua argumentação, procurava demons- 
trar que, mesmo tendo passado por significativas mudanças, a instituição mantinha-se organizada segundo um modelo rígido, o que podia ser atestado pelas exigências dos programas, exames e concursos. Desse modo, apesar das mudanças pelas quais passara a escola, desde seus tempos de estudante, o regime de trabalho intenso, contínuo e repetitivo, no qual não se reservava nenhum espaço para os cuidados com o corpo e para as práticas de exercício dos músculos, persistia como o traço mais característico.

As reflexões de Lavisse inscrevem-se em um projeto de renovação pedagógica que encontra seus fundamentos na higiene e na fisiologia e é nessa perspectiva que podem ser compreendidas suas críticas ao regime escolar. Assim, a par do diagnóstico dos problemas que caracterizavam a organização do trabalho escolar, o conferencista convida os ouvintes a se engajarem no projeto de construção de uma nova escola. O sucesso dessa empreitada pressupunha o reconhecimento das relações estreitas entre o corpo e o espírito, exigindo do professor uma atitude de respeito e cuidado com o corpo do aluno, assim como a adesão às práticas regulares de asseio, concebidas como possibilidade de preservação da saúde. A almejada renovação pedagógica alicerçava-se, desse modo, sobre a necessidade do conhecimento, por parte do professor, das formas de alcançar o vigor corporal, da compreensão das vantagens do repouso e do exercício, bem como do reconhecimento da urgência de mudanças no regime escolar, pautadas no reconhecimento de que, no conjunto das práticas escolares cotidianas, a cópia mal-escrita e as mãos sujas dos alunos revestiam-se do mesmo grau de importância.

Referindo-se à sua atuação na Escola Normal, o conferencista dá destaque às frentes de atuação em que estava envolvido, as quais respondiam a um duplo propósito: dotar a instituição de instalações higiênicas e, ao mesmo tempo, implantar um modelo de formação de professores que incluía a participação dos médicos. Em seu diálogo com os professores em formação, esses profissionais se responsabilizariam por oferecer orientações sobre o desenvolvimento das crianças, tanto do ponto de vista físico quanto intelectual, ensinando-lhes "o que é a planta humana da qual eles serão os jardineiros" e preparando-os para os cuidados exigidos por essa "pequena planta" (LAVISSE, 1906), a qual, em suas palavras, deveria ser cultivada com afeição e amor, em conformidade com os ditames da ciência. 


\section{Em nome da saúde e do desenvolvimento integral da criança}

Uma boa bigiene escolar que é nosso objetivo comum não pode deixar de se beneficiar da nossa concordância e do apoio que vocês quiserem nos oferecer.

(BUT'TE, 1906, p. 15)

As palavras proferidas por Butte, representante da Sociedade dos Médicos-Inspetores de Paris, na sessão de abertura do II Congresso de Higiene Escolar e Pedagogia Fisiológica, procuram ressaltar as vantagens que adviriam do consenso em torno das iniciativas de inspeção médica das escolas, ao mesmo tempo em que oferecem indícios das disputas que acompanharam a constituição do campo da higiene escolar. Disputas essas que punham em cena os interesses dos médicos (incluídos os médicos inspetores escolares, os médicos de família e os especialistas); dos professores e diretores de estabelecimentos de ensino; assim como das famílias, num momento em que as questões ligadas à saúde e ao desenvolvimento das crianças se cruzavam com o enfrentamento dos vários problemas que acompanharam o processo de universalização da escola primária na França.

Nesse sentido, as comunicações apresentadas versaram sobre um rol de temáticas que recobriam desde a implantação dos serviços de inspeção médica das escolas, em suas relações com os critérios de seleção e nomeação dos médicos inspetores, até as diversas dimensões do trabalho pedagógico, consideradas do ponto de vista das suas repercussões sobre a saúde das crianças. Exemplares, em relação a essas questões, são as comunicações que tomam como objeto de estudo o tempo escolar, a criação de escolas e classes especiais para crianças consideradas "débeis", o programa de higiene a ser ensinado às crianças, os dispositivos de registro dos dados individuais dos alunos.

Tendo em vista a importância assumida pelas discussões sobre o exame e o registro das características individuais das crianças em suas relações com a institucionalização da inspeção médica das escolas, no âmbito desse evento, privilegiou-se o exame de seis comunicações: duas delas versando sobre a temática da inspeção e as demais sobre as fichas e cadernetas sanitárias ${ }^{6}$. Trata-se, no primeiro caso, das comunicações apresentadas na sessão presidida pelo Prof. Courmont, sob os títulos: "Inspection médicale des écoles primaires, son fonctinnement, 
recrutement des médecins inspecteurs des écoles", de autoria de Méry, professor encarregado do curso de clínica médica infantil e "Rôle et mode de nomination des médecins inspecteurs des écoles", de Cornet, delegado da Sociedade dos Médicos-Inspetores da cidade de Paris.

As conclusões das teses de Méry e Cornet, aprovadas pelos congressistas, apontam para a necessidade de medidas que assegurassem a institucionalização mais adequada da inspeção médica das escolas, incidindo sobre questões que se referem aos seus objetivos, abrangência, meios de atuação, constituição do quadro de médicos inspetores, tanto do ponto de vista da sua seleção quanto da sua nomeação.

Em relação aos objetivos a que visava essa instituição, o congresso aprova três orientações, que merecem os aplausos do representante suíço, Stocker, uma vez que coincidiam com as recomendações discutidas no último congresso suíço de higiene escolar, realizado em Lucerne, no mês anterior. As conclusões aprovadas previam que à inspeção médica das escolas caberia:

$1^{\circ}$. Assegurar a vigilância higiênica dos edifícios e do mobiliário escolar;

$2^{\circ}$. Velar pela profilaxia das moléstias transmissíveis;

3. Assegurar o desenvolvimento integral da cultura física e intelectual da criança. (MÉRY, 1906, p. 113)

Discorrendo sobre o funcionamento da inspeção médica das escolas primárias, a comunicação de Méry assinala o interesse que a questão vinha despertando, sobretudo a partir do congresso de 1903; interesse esse que podia ser evidenciado, entre outras formas, pelo crescente número de artigos na imprensa médica e pedagógica, pelo significativo lugar da temática nos congressos e pela atividade da Liga dos Médicos e das Famílias?. Do ponto de vista das questões presentes no debate teórico sobre a temática, identifica quatro tópicos fundamentais: a necessidade do exame dos alunos e do estabelecimento da ficha individual; a utilidade do agrupamento das crianças segundo suas aptidões e a consequente organização de classes especiais para as crianças consideradas anormais; a importância de uma campanha contra a tuberculose organizada a partir da escola; e, por fim, a necessidade de promover a instrução dos médicos em higiene escolar".

Defendendo como papel dos serviços de inspeção médica das escolas a responsabilidade de velar pela higiene da escola e dos alunos, 
tanto do ponto de vista físico quanto do intelectual, Méry divide sua comunicação em quatro tópicos, os quais correspondem aos aspectos que deveriam ser contemplados pela ação do médico escolar: a vigilância higiênica do edifício e do mobiliário escolar; a profilaxia das moléstias transmissíveis; a vigilância sanitária da criança, compreendendo o exame e o registro na ficha sanitária individual; a educação sanitária das crianças e dos mestres. $\mathrm{O}$ amplo rol de atribuições que cabiam a esse profissional levantava, evidentemente, indagações em relação à sua intervenção em questões de natureza pedagógica, como os programas, os horários, a fadiga intelectual e a própria composição das classes escolares. Quanto a essa questão, Méry apoiava-se nas considerações de Chabot, em artigo publicado na Revue Pédagogique, no qual o autor afirmava que:

o médico deve proteger a escola das doenças contagiosas ou deter o seu desenvolvimento. Ele deve reconhecer as crianças ameaçadas ou já atingidas mesmo sem apresentar manifestações; convencer os pais a buscar tratamento para os doentes; identificar os anormais; controlar com autoridade os serviços de asseio, de ventilação e de aquecimento; controlar a vida física dos alunos, incluindo o seu regime de trabalho. (apud MÉRY, 1906, p. 80)

Dois aspectos assumem centralidade na comunicação de Méry: um deles refere-se à questão da seleção dos médicos inspetores, a qual se articula intimamente à discussão sobre a formação médica e o lugar que deveria ser conferido, no âmbito dessa formação, ao estudo das questões pedagógicas, aspecto já tematizado pelo autor no primeiro congresso, como registra Bañuelos (2000). O outro diz respeito ao exame e ao registro das características das crianças, temática recorrente no conjunto das comunicações examinadas, cujo tratamento indica a preocupação latente com a classificação das crianças, que acompanhou a institucionalização do ensino obrigatório, impondo-se na agenda dos médicos higienistas e ocupando lugar de destaque nas discussões em torno dos objetivos a que deveria visar a inspeção médica das escolas.

Diante da indagação sobre a constituição do corpo de profissionais que deveriam se responsabilizar pela inspeção das escolas e dos alunos, Méry posiciona-se contrário à escolha de médicos especializados em higiene, postulando a necessidade de se introduzir o ensino sistemático de noções de higiene escolar em todas as escolas médicas, o qual contemplaria não apenas temas médicos, mas também questões peda- 
gógicas e, de modo mais específico, aquelas que se inseriam no campo da então denominada pedagogia fisiológica, considerada um domínio específico da medicina. Sobre a relevância desses conhecimentos na formação médica, destaca:

Com esses dados sobre o corpo e a alma da criança no estado normal ou patológico, poder-se-á abordar, nesse ensino, as questões de pedagogia que são do domínio da medicina, quer dizer, a pedagogia fisiológica.

Nós cremos pois que, em tal ensino, se deve, num primeiro momento, dar lugar à higiene dos locais e do mobiliário, à higiene individual da criança, ao estudo das doenças escolares, de todos os problemas de crescimento; em seguida, deve ser reservado um espaço para o estudo da psicologia e, enfim, esse curso será concluído com a exposição das partes da pedagogia pelas quais a medicina deve se interessar, quer dizer, a pedagogia fisiológica. Por último, deve-se reservar um lugar para os métodos de ensino da higiene aos alunos, de modo a preparar os médicos para exercer o papel muito desejável de educadores de higiene. (MÉRY, 1906, p. 103-104)

A enunciação da responsabilidade do médico por todo esse rol de questões pedagógicas, que se faz acompanhar, na comunicação apresentada por Cornet, de todo um conjunto de reivindicações em relação às condições de trabalho, remuneração, formas de seleção e nomeação, bem como do direito de assento nos conselhos escolares, podem ser indicativas do tipo e do grau das disputas, tensões e conflitos entre médicos e professores que acompanharam a institucionalização desse órgão, que visava à vigilância constante da escola e das crianças sob sua responsabilidade. Indícios dessas disputas e das representações dos médicos em relação ao seu protagonismo nessa empreitada também podem ser encontrados no discurso proferido por Mathieu, presidente da Liga dos Médicos e das Famílias, na sessão de abertura do congresso, ao destacar a responsabilidade que cabia aos médicos de conquistar a adesão dos professores à "pedagogia natural, respeitosa das prescrições da higiene, baseada antes de tudo sobre o conhecimento das leis do desenvolvimento fisiológico e psicológico da criança” (MATHIEU, 1906, p. 9).

Outro indício do cenário de disputas reinante é a discussão sobre os requisitos que deveriam ser obedecidos no preenchimento dos cargos de médico-inspetor em Paris. Conforme sugeria Cornet, o médico deveria ter idade mínima de 30 anos e um mínimo de cinco anos de experiência profissional, critério cujo estabelecimento visava a contornar os constran- 
gimentos a que estariam expostas as meninas entre 14 e 15 anos de idade, submetidas ao exame físico por médicos muito jovens.

$\mathrm{O}$ intenso debate suscitado pela tese de Cornet evidencia a importância que a definição de questões ligadas ao estatuto profissional do médico inspetor escolar assumia no momento, bem como a importância do evento para a definição de aspectos fundamentais em relação à institucionalização da inspeção médica. As discussões a que deu lugar resultaram na aprovação de orientações quanto ao perfil desse profissional, às formas de seleção e nomeação, procurando-se evitar as injunções políticas e a instabilidade que marcavam os processos de contratação. Embora algumas dessas recomendações se referissem especificamente à cidade de Paris, sua aprovação mostrava-se fundamental na definição dos moldes segundo os quais se deveria configurar essa instituição, bem como das relações em que deveriam se colocar médicos, professores e pais, quando se tratava da preservação da saúde das crianças que frequentavam as escolas públicas e privadas dos diferentes níveis.

A discussão sobre a questão do exame dos alunos e da elaboração das fichas individuais como instrumentos necessários para a garantia de adequada vigilância sanitária da criança, embora remetida para a sessão organizada em torno dessa temática, mereceu tratamento minucioso de Méry. Reclamando a uniformidade dos métodos de exame, o autor defendia que o ingresso da criança na escola fosse acompanhado de um conjunto de procedimentos que possibilitassem constatar o estado de saúde em que se encontrava, os quais incluíam medição de peso, altura e perímetro torácico; avaliação de audição, visão e respiração; investigação sobre o funcionamento dos diferentes órgãos.

Os dados levantados nesse exame inicial, acrescidos de informações sobre os antecedentes hereditários e pessoais, deveriam ser registrados em fichas individuais, as quais seriam confiadas unicamente aos médicos, aspecto que parece ter sido alvo de grande inquietação por parte dos pais. Os propósitos de identificação de anormalidades e classificação dos escolares a que visavam esses procedimentos não poderiam ser mais explícitos do que no trabalho de Méry. Nesse sentido, a indagação que levanta e a classificação que propõe são extremamente significativas do papel que deveria caber à inspeção médica das escolas, na definição de aspectos cruciais da organização da escola primária e na configuração do público escolar: 
Uma vez estabelecidas as fichas, quais serão as conseqüências? Para que elas vão servir?

Para a seleção das crianças normais e anormais.

Pode-se dividir as crianças anormais em três classes:

$1^{\circ}$. Anormais fisiológicos, quer dizer aqueles que são anormais nas funções exigidas pela vida escolar, como a visão e a audição;

$2^{\circ}$. Os anormais em relação à saúde geral, compreendendo sobretudo os predispostos à tuberculose e que eu chamarei de bom grado os anormais orgânicos;

3․ Os anormais pedagógicos. (MÉRY, 1906, p. 92)

No caso dos considerados "anormais pedagógicos", o autor destaca a insuficiência do exame de ingresso para sua identificação, a qual exigia a colaboração entre o médico e o professor, ressaltando, nesse sentido, ser dever do professor solicitar o exame médico para as crianças cujo trabalho intelectual não se desenvolvesse de forma regular. A classificação dos alunos não se inscrevia, segundo Méry, no campo da mera curiosidade; exigia medidas práticas, as quais se consubstanciavam, no caso dos considerados "anormais fisiológicos", na determinação dos lugares que tais crianças deveriam ocupar no interior das salas de aula e, no que se referia aos considerados "anormais pedagógicos", o encaminhamento para as classes especiais, cuja criação se apresentava como uma necessidade inadiável.

O exemplo a que recorre para pensar essa questão é o da Alemanha, onde os estudantes supostamente pouco dotados eram eliminados das salas de aula regulares, ao final de um trimestre de observação, mediante exame realizado pelo médico, em conjunto com o diretor da escola. A trajetória escolar dessas crianças, a partir desse momento, se definiria pelo seu desempenho, havendo casos de crianças que, após alguns anos nessas classes, conseguiam retornar ao ensino regular, enquanto outras, consideradas menos dotadas, seguiam a escolaridade em classes auxiliares ${ }^{10}$. Em se tratando dos supostos "anormais orgânicos", não cabiam medidas propriamente escolares, já que os problemas que apresentavam se circunscreviam ao campo da saúde, restringindo-se a atuação das autoridades educacionais à criação de escolas à beira-mar, no campo ou de colônias escolares.

Semelhantes preocupações são esboçadas por Cornet, que indaga sobre o destino a ser dado às crianças eliminadas das classes regulares, com base nos dados do exame médico. Sua indagação, 
aproximando-se das inquietações de Méry, põe em pauta um tema candente no período: o do acesso à escola dos setores populares, propiciado pela obrigatoriedade da escolarização, e do destino das crianças que não se adaptavam ao regime escolar:

Mas o que fazer destas crianças eliminadas, de modo a corresponder às exigências da lei de instrução primária obrigatória, e não atendê-las do ponto de vista pedagógico, a menos que elas sejam crianças retardadas e idiotas?

Nós não temos na França classes auxiliares e parece lógico que se deveria em primeiro lugar enfrentar essa questão. (CORNET, 1906, p. 106)

\section{0 conhecimento da criança, a orientação das famílias e a renovação pedagógica}

Discutida por Méry, a questão da adoção da ficha sanitária individual como dispositivo de registro dos dados colhidos no exame médico das crianças mereceu, pela sua relevância, uma sessão especial, na qual se discutiram longamente aspectos como: o seu formato, os dados que deveriam ser registrados e a responsabilidade por esses dados. Presidida pelos professores Chantemesse e Pinard, a sessão reuniu as seguintes comunicações: "Le livret sanitaire à l'école", do professor Teissier, de Lyon; "Hygiène de l'enfant à l'école”, de Henri Gourichon; "Le livret scolaire de santé", de César Roux, médico inspetor das escolas da cidade de Nice; e "Le dossier sanitaire de l'écolier, base nécessaire de la pédagogie experimentale et du perfeccionnement individuel”, de Robert Dinet.

Se a necessidade do registro das características infantis parecia inquestionável, pairavam dúvidas sobre o formato da ficha, sua extensão e as providências a serem tomadas depois que o aluno deixasse a escola, de modo a assegurar o sigilo das informações. As quatro comunicações apresentadas põem em cena, ao lado das discussões sobre esse leque de questões, modelos de caderneta sanitária em uso em algumas escolas, naquele momento. Como conclusões dessa sessão, o congresso aprovou o seguinte texto:

$1^{\circ}$. A ficha e a caderneta sanitária têm por objetivo e utilidade:

Permitir aos médicos escolares controlar mais facilmente o crescimento e o estado de saúde dos alunos, e dar aos pais informações de interesse sobre a saúde de seus filhos; 
Fornecer aos mestres as informações de que eles têm necessidade do ponto de vista pedagógico;

Fornecer aos alunos informações úteis para a escolha da sua profissão e ao longo de toda a sua vida.

$2^{\circ}$. A ficha e a caderneta sanitária devem ser de propriedade da família; elas lhe serão fornecidas assim que a criança deixar o estabelecimento escolar.

$3^{\circ}$. As fichas ou cadernetas serão de um mesmo tipo, a definir:

para as escolas maternais;

para os estabelecimentos de ensino primário;

para os estabelecimentos de ensino secundário e similares.

4. O tipo da ficha será estabelecido por uma comissão mista de pedagogos e médicos. (1906, p. 300)

A experiência adquirida com a adoção de fichas ou cadernetas, em algumas escolas francesas ${ }^{11}$, autoriza os profissionais que intervêm na discussão dessas questões a defender a obrigatoriedade de uma ficha sanitária individual em todas as escolas francesas, públicas ou particulares. Visando a garantir sua efetiva utilização, chega-se a um consenso em torno da ideia de que essa ficha deveria ser simples e concisa, reunindo apenas as informações consideradas indispensáveis.

Partindo da afirmação da prioridade que a instituição de uma caderneta sanitária individual para todos os estabelecimentos de ensino, públicos ou privados, de todos os níveis, deveria assumir nos projetos da Liga dos Médicos e das Famílias, Teissier procura marcar, em sua comunicação, o descompasso entre as posições assumidas em relação à temática nos congressos de higiene escolar e a inércia dos poderes públicos franceses. Assinala, nesse sentido, que embora uma circular do ministro da Instrução Pública, de outubro de 1902, houvesse determinado a adoção de uma ficha sanitária para todos os alunos internos dos estabelecimentos públicos de ensino secundário, o dispositivo legal não se fez cumprir.

A interrogação sobre as causas desse fracasso não se limita ao exame da ação do Estado. Seu tratamento põe em cena alguns aspectos recorrentes nas teses apresentadas nessa sessão, os quais são bastante significativos, quando se procura compreender os modos como os sujeitos envolvidos nas disputas, que marcaram a institucionalização da inspeção médica, reagiram a essa intervenção dos médicos higienistas em seus fazeres cotidianos. Entre as razões apontadas por Teissier, estariam: o contraste entre as práticas que essa medida visava a instituir e as rotinas 
instituídas nas escolas, as dificuldades materiais de execução e os conflitos com as famílias, os quais, como indica a leitura do conjunto de comunicações apresentadas nessa sessão, teria na questão do segredo profissional sobre as características das crianças o seu principal móvel.

Postulando a necessidade de uma caderneta sanitária uniforme, simples e prática, mas, ao mesmo tempo, completa, o autor apresenta um projeto desenhado segundo o modelo defendido por Letulle em congresso anterior, o qual contemplava dados de identificação, antecedentes familiares, informações sobre vacinação, indicação de infecções sofridas durante a vida escolar, além de dados levantados nos exames anuais. $\mathrm{O}$ conjunto de informações registradas nessa caderneta permitiria uma leitura criteriosa do estado geral de saúde da criança, com base no qual seria possível ao médico orientar sua classificação, em conformidade com aptidões visuais e auditivas; oferecer orientações quanto ao regime alimentar, jogos e exercícios; e, ainda, avisar os pais sobre as doenças que ameaçavam os filhos.

Na comunicação de Teissier, a Alemanha é erigida em exemplo do papel que poderia ser desempenhado por esse dispositivo na preservação da saúde das crianças, atestando a possibilidade de se quebrarem as resistências das famílias, por meio de um trabalho sistemático e sério dos médicos inspetores. Embora a preocupação com as questões pedagógicas não esteja ausente nas argumentações do autor, a ênfase recai sobre a necessidade da prevenção de determinados quadros mórbidos, justificando-se as medidas propostas pelos benefícios que representavam para a saúde pública. Medidas que se faziam necessárias em função da suposta omissão das famílias dos trabalhadores, as quais não estavam em condições de cuidar da saúde dos filhos, quer pela falta de tempo, quer pela insuficiência de educação sanitária.

Semelhantes argumentos são acionados por Henri Gourichon, que situa a atuação da inspeção das escolas, no campo da higiene preventiva, identificando como dificuldades para a sua adequada implementação: os preconceitos, a negligência, a má vontade e a indiferença dos pais, bem como a fragilidade dos dispositivos legais. Como prova dessa fragilidade, cita a ineficiência do regulamento que estabelecia a obrigatoriedade da inspeção de asseio, bem como a proibição da permanência das crianças que se apresentassem em estado de asseio inadequado. $\mathrm{O}$ descumprimento do dispositivo legal podia ser atestado cotidianamente, 
segundo destacava, pela presença, nas escolas, sobretudo em bairros periféricos, de "crianças com vestimentas sujas, esfarrapadas, com o rosto e as mãos negras de sujeira, com os cabelos despenteados, pontilhados de lêndeas e piolhos, cujos pais negligentes se preocupam muito pouco" (GOURICHON, 1906, p. 256). Diante dessa situação, os médicos sentiam-se, segundo a reflexão do autor, absolutamente desarmados, já que o afastamento dessas crianças da escola significava, na maioria dos casos, a possibilidade de liberá-las das tarefas escolares, para vê-las vagabundeando pelas ruas.

No que se refere às fichas individuais a serem adotadas nas escolas, Gourichon defendia que, além dos dados colhidos no exame físico, anotações sobre faltas ocasionadas por doenças e resultados das revacinações, os médicos inspetores deveriam registrar informações sobre os antecedentes familiares das crianças, levantadas em entrevistas com os pais, em presença do diretor da escola. Como na comunicação feita por Méry, aqui também figura, entre os objetivos a que responderia o levantamento desses dados, a possibilidade de identificação dos alunos considerados "anormais". Bastante significativas, em relação a esse aspecto, são as posições do autor quanto à recente nomeação, pelo ministro da Instrução Pública, de uma comissão encarregada do estudo da questão:

Este exame nos permitirá descobrir os anormais físicos, intelectuais e morais. Não entraremos no estudo das conseqüências que daí resultarão. Nós vos lembramos que foi recentemente instituída uma comissão pelo Ministério da Instrução Pública, com o objetivo de estudar as condições mediante as quais as prescrições da lei de março de 1882 sobre a obrigatoriedade do ensino primário poderão ser aplicadas às crianças anormais de ambos os sexos e lamentamos que essa comissão não conte, entre os seus membros, com médicos-inspetores das escolas de Paris. (GOURICHON, 1906, p. 263)

Embora Gourichon não faça menção aos nomes indicados pelo ministro, não é demasiado supor que se trata da comissão composta por Binet e Simon para estudar a situação das crianças francesas que não conseguiam sucesso nas aprendizagens escolares, cujos resultados redundariam na criação do ensino especial na França (JATOBÁ, 2002). As críticas veladas do autor constituem-se em mais um indício das disputas em torno da legitimidade dos campos de conhecimento que, naquele momento, tomavam como objeto de estudo e intervenção a criança em 
sua inserção na escola, ao mesmo tempo em que indiciam o deslocamento dessas questões do campo da higiene para o da psicologia.

Partindo dos mesmos pressupostos sobre a utilidade de um dispositivo de registro dos dados resultantes do exame médico como meio de velar pela saúde das crianças na escola, a comunicação de César Roux, médico inspetor das escolas de Nice, apresenta a experiência de implementação da caderneta sanitária nas escolas comunais dessa municipalidade. Visando a contornar os problemas ligados ao segredo profissional, aspecto recorrente nas comunicações apresentadas nessa sessão e que tornava as práticas de exame e registro alvo das objeções dos pais, a caderneta estava dividida em duas partes: uma primeira em que estavam registrados dados sobre o aluno, que "em nada ferem a susceptibilidade dos pais" (ROUX, 1906), a qual deveria ficar em poder do aluno, e uma segunda parte na qual eram consignados dados confidenciais, os quais permaneciam sob responsabilidade do médico inspetor. É curioso observar, acompanhando o relato de Roux, que as cadernetas sanitárias não foram concebidas apenas como dispositivo que permitiria registrar os dados dos alunos, consignando um conjunto de representações sobre a criança e seu desenvolvimento. Algumas delas, como o modelo adotado em Nice, serviram também de suporte para a difusão de noções de higiene, incidindo sobre aspectos como a importância do asseio corporal e do meio, as posturas a serem adotadas durante os exercícios de leitura e escrita, os perigos do alcoolismo e do fumo.

A reflexão sobre as relações entre a higiene escolar e a pedagogia encontra tratamento mais amplo e sistemático na comunicação de Robert Dinet, cujo título é bastante sugestivo das dimensões pedagógicas envolvidas na discussão sobre os dispositivos de registro das características individuais das crianças: "Le dossier sanitaire de l'écolier, base nécessaire de la pédagogie experimentale et du perfeccionnement individuel". Sobre a utilidade e a necessidade da medição e do registro das características infantis, o autor destaca que não se tratava de uma ideia recente, procurando situar, ainda na primeira metade do século XIX, estudos que recomendavam tais práticas. Entretanto, segundo destaca o autor, foi o medo provocado pela propagação da tuberculose que justificou as primeiras iniciativas do Estado, no final do século. $\mathrm{O}$ balanço das posições assumidas por renomados profissionais, em congressos anteriores e nas reuniões da Liga de Médicos e Famílias ${ }^{12}$, constitui-se em 
estratégia discursiva por meio da qual Dinet procura conferir legitimidade ao argumento da centralidade da ficha sanitária individual na profilaxia das doenças escolares, como também na reorientação da pedagogia, residindo na ênfase dada a esse aspecto uma marca distintiva da sua comunicação em relação às demais. Tal dispositivo assume o lugar de "pedra de fundação", "fundamento de qualquer reforma" no campo da educação (DINET, 1906), devendo se consubstanciar como questão prioritária na agenda dos membros da liga.

A extensão dessa ficha e os dados que ela deveria reunir constituem-se em aspectos que preocupam Dinet, que traduz suas inquietações em perguntas do tipo: é uma ficha que nós queremos? Que tipo de ficha? $\mathrm{O}$ que devemos incluir nessa ficha? $\mathrm{O}$ registro dos dados sobre peso, altura e perímetro torácico seria suficiente para o estudo sobre a influência do trabalho escolar na fadiga intelectual e para a constituição da pedagogia experimental? Ou seria necessário, como propunha Letulle, uma caderneta mais detalhada, que registrasse as informações colhidas no exame somático completo? As cadernetas sanitárias propostas por César Roux e Tessier, naquela mesma sessão, as quais registravam um conjunto de dados sobre o estado físico do aluno, os seus antecedentes familiares e as doenças anteriores seriam os modelos mais apropriados?

A esse conjunto de questões, o autor responde procurando demarcar que, embora se pudesse considerar uma grande conquista a implementação desse tipo de fichas e cadernetas em todos os estabelecimentos de ensino, considerando sua utilidade para os fins de vigilância da saúde das crianças, era preciso ir além, quando se tinha em vista os propósitos de reorientação do trabalho pedagógico com base nas exigências da pedagogia experimental. Para tanto, reclamava a adoção de um dossiê médico-pedagógico, que deveria reunir, além das informações previstas para as fichas, anotações minuciosas sobre o desenvolvimento físico e psíquico da criança e observações pedagógicas fornecidas pelo professor.

Tal dossiê possibilitaria o estudo das relações entre aptidões físicas e intelectuais, podendo constituir-se, futuramente, em instrumento precioso para a orientação dos alunos na escolha profissional. O propósito era claro: diminuir os fracassos e possibilitar que cada um utilizasse ao máximo suas aptidões, em benefício da sociedade. Nesse empreendimento, ao professor caberia a tarefa de oferecer dados que 
permitissem a avaliação das relações entre o estado de saúde e o rendimento do aluno, tais como: conduta, aplicação ao trabalho, inteligência, facilidade para certas matérias, sentimentos morais, gostos artísticos.

Uma investigação dessa envergadura, certamente, não deixaria de encontrar oposições, já que, como pondera o autor, não havia sido possível, até então, estabelecer nem mesmo uma ficha mais simples. Uma forma de contornar essas dificuldades era a utilização de uma ficha mais simples para os alunos da escola primária, dado que se tratava de um contingente mais numeroso de crianças, reservando-se o dossiê para os alunos do ensino secundário, nível de escolarização que, pela sua duração, número de alunos e de professores, poderia se constituir em campo para as pesquisas sobre a pedagogia experimental e a cultura racional da criança, oferecendo matéria para a reflexão pedagógica em todos os níveis de ensino.

Atento às dificuldades que poderiam se apresentar ao empreendimento, mesmo que restrito apenas ao ensino secundário, Dinet situa os possíveis obstáculos em dois planos: de um lado, as restrições dos próprios médicos e dos professores e, de outro, as resistências dos pais. Do ponto de vista dos médicos, as dificuldades adviriam do deslocamento do seu papel de uma vigilância voltada para a profilaxia das doenças contagiosas para uma vigilância que tinha em vista o desenvolvimento fisiológico da criança, em sua relação com os problemas pedagógicos, tarefa mais complexa e que demandaria tempo maior. Em relação a esses obstáculos, entretanto, o autor lembra que os médicos não estariam isolados, já que contariam com o apoio dos professores na observação das crianças, resultando dessa colaboração a boa cultura física e intelectual dos alunos.

Pensar na colaboração entre médicos e professores significava ter em conta que as relações entre esses profissionais poderiam não ser tão simples, mas antes pontuadas pelas desconfianças dos professores, $\mathrm{O}$ que o leva a indagar: "não se deve temer que eles vejam com uma desconfiança algo irônica essas inovações que os médicos se empenham em introduzir no ensino? Não se deve temer que eles nos vejam com escárnio ao nos apresentarmos como reformadores de uma área que não é nossa?" (DINET, 1906, p. 290). Quanto a essa questão, pondera que era necessário acalmar os professores, o que poderia ser feito lembrando-lhes que a medicina e as ciências afins, como a fisiologia, muito teriam a 
oferecer à pedagogia, abrindo-lhe novos horizontes. Segundo suas palavras, da colaboração entre o médico e o professor resultaria um conhecimento mais amplo desse "enigma", que era a criança.

O lugar de superioridade conferido ao conhecimento médico é inequívoco na reflexão de Dinet sobre os possíveis confrontos entre médicos e professores, oferecendo elementos para uma leitura das representações sobre si mesmos, sobre os professores, as crianças e a instituição escolar, produzidas pelos médicos, nessa disputa por legitimar suas concepções:

Nós substituiremos um conhecimento impreciso e muitas vezes superficial de sua personalidade [da criança] por um conhecimento mais profundo graças à experimentação; isto porque nós, médicos, conhecendo os felizes resultados da experimentação em medicina, afirmamos que ela pode oferecer semelhantes resultados em pedagogia, já que a medicina e a pedagogia, além de numerosos pontos de contato, são duas ciências que apresentam muitas semelhanças, tanto pelo objeto dos seus estudos como pelos seus métodos. (DINET, 1906, p. 290)

Apoiando-se na autoridade de Dumesnil, professor responsável pelo curso de ciências da educação na Faculdade de Letras da Universidade de Grenoble, o autor lembra que o recurso ao método experimental consubstanciava-se em ponto comum entre a "arte médica" e a "arte pedagógica" (apud DINET, 1906). Sobre esse tema, o discurso de Dinet não poderia ser mais claro. Se ambas deveriam se articular em torno desse método, a relação de subordinação dos professores aos médicos era a única possibilidade vislumbrada para a reconfiguração do trabalho pedagógico. Entretanto, longe de se constituir em obstáculo intransponível, Dinet aposta na possibilidade de superação de possíveis conflitos, para a qual concorreriam a colaboração e a boa vontade dos professores, na implantação do dossiê médico-pedagógico.

Tal colaboração se expressaria por meio da dedicação do professor ao estudo sistemático dos alunos, à pesquisa sobre os defeitos apresentados por eles e suas causas, ao registro de todos os indícios que favorecessem o estabelecimento de um diagnóstico preciso, o qual caberia, em última instância, ao médico. Assim:

Este aluno, apreciado por seu professor porque tem o espírito desperto e respostas vivas, e este outro, que é mal visto porque é colérico, sujeito a ausências e vítima de torpor intelectual se revelarão ao médico, o primeiro 
como um histérico, o segundo como um epiléptico, por exemplo; e, neste caso, o tratamento prontamente instituído poderá ter uma influência considerável não apenas sobre a forma pela qual eles aproveitarão o ensino que lhes é dado, como também sobre o seu futuro. (DINET, 1906, p. 292)

Em suas reflexões, Dinet não ignorava as resistências que deveriam ser vencidas na implantação de uma pedagogia fisiológica e individual calcada no estudo científico e experimental da criança. Não lhe era estranha a possibilidade de que alguns professores se recusassem a seguir essa orientação, permanecendo fiéis à sua rotina, postura que também se encontrava entre os próprios médicos. As resistências mais difíceis de serem vencidas, porém, situavam-se em outro âmbito, segundo as reflexões do autor. Tratava-se da oposição das famílias, incrédulas em relação ao segredo profissional e inseguras quanto ao destino que seria dado às informações sobre suas crianças e seus antecedentes familiares.

Referindo-se à atuação da liga, o autor evidencia a fragilidade dessa aliança entre médicos e famílias, bem como os propósitos que presidiram a criação dessa entidade, num discurso crítico em relação às posições recorrentes nas comunicações apresentadas no congresso, que reafirmavam a negligência das famílias:

O título de nossa Liga dos Médicos e das Famílias parece atualmente um tanto irônico quando se percebe a unanimidade com a qual, na primeira sessão deste Congresso, os oradores se voltaram contra as famílias para demonstrar a sua ignorância em higiene, sua indiferença ou mesmo sua má vontade.

Eu creio que será difícil, ainda por muito tempo, levar as famílias a compartilhar de nossas posições, a compreender a importância da caderneta sanitária, desta pedagogia experimental; sua educação será dolorosa, e penso que será necessário esperar, para garantir sua plena adesão a esse sistema, que as próximas gerações, educadas segundo esses métodos, compreendam naturalmente essa necessidade. (DINET, 1906, p. 294)

Se a tarefa era árdua, não cabia, entretanto, desanimar. Nesse sentido, o autor destaca o valor de uma campanha de propaganda que, lançando mão de conferências, pudesse atingir as famílias, levando-lhes as ideias dos médicos e procurando convencê-las da responsabilidade que lhes cabia na preservação e no aprimoramento das capacidades físicas e intelectuais dos seus filhos. No coração da oposição e da hostilidade das famílias à implantação de uma caderneta sanitária ou de um dossiê 
médico-pedagógico, Dinet situa “o temor de ver reveladas suas taras pessoais e as de suas crianças" (DINET, 1906).

Concluindo sua comunicação, o médico conclama os ouvintes a se reunirem em torno de um projeto de reconfiguração da escola que permitisse constituí-la em meio de cultura racional e de aperfeiçoamento do aluno, obra que só poderia se concretizar pelo estudo das aptidões das crianças calcado no emprego de uma pedagogia fundada em pressupostos científicos e experimentais. Na configuração dessa ciência pedagógica, as cadernetas ou os dossiês, produzidos a par da colaboração entre médicos, professores e famílias, figuram como instrumentos indispensáveis.

\section{Notas finais}

Observação atenta, exame criterioso e exaustivo, registro detalhado e análise dos dados consistiam nos elementos que, como evidenciam os discursos dos médicos franceses, permitiriam a constituição de um conhecimento científico sobre a criança, com base no qual seria possível conduzir o trabalho pedagógico. Na construção dessas novas certezas sobre a infância, que orientariam a distinção entre a criança normal e a criança anormal, guiando, ao mesmo tempo, as decisões sobre o lugar apropriado para a educação de uma e outra, assim como sobre os métodos e processos de ensino mais adequados, os médicos higienistas se defrontaram com inúmeras oposições, movendo-se com certa cautela em meio a essas disputas e procurando construir consensos em torno da afirmação da medicina como única ciência que poderia conduzir ao conhecimento preciso sobre a criança, em suas características físicas e intelectuais. $\mathrm{Na}$ busca de produção desses consensos e de convencimento dos seus possíveis colaboradores, era preciso lançar mão de algumas estratégias.

Nesse empreendimento, é possível pensar a organização da Liga dos Médicos e das Famílias, assim como a realização de eventos, a exemplo do II Congresso de Higiene Escolar e Pedagogia Fisiológica, como algumas dessas estratégias. Cabe, nesse sentido, chamar a atenção para a importância desses fóruns na legitimação da atuação desses profissionais no âmbito da escola. Reunindo um conjunto significativo de profissionais, majoritariamente do campo da medicina, oriundos de diferentes países, assim como alguns professores e pais, eventos dessa 
natureza participaram da produção de uma agenda e de uma pauta comum construída pela recorrência das temáticas, pela consagração das autoridades na discussão dessas temáticas e, ao mesmo tempo, pela reafirmação das recomendações aprovadas nos congressos. Tais estratégias permitiram, ao mesmo tempo, pôr em circulação um conjunto de modelos de organização da escola, de representações sobre a criança e a família, de concepções sobre o desenvolvimento infantil, bem como de objetos materiais, como as fichas e cadernetas sanitárias, por meio das quais se procurou construir um conhecimento científico sobre a infância como base para a reorientação das práticas escolares.

\section{Referências}

BAÑUELOS, A. T. La higiene escolar: un campo de conocimiento disputado. Areas Revista de Ciencias Sociales, Murcia (Espanha), n. 20, p. 73-94, 2000.

BUTTE. Allocution de Butte. In: LIGUE DES MÉDECINS ET DES FAMILLES. Deuxième Congrès d'Hygiène Scolaire et de Pédagogie Physiologique, Paris, 1905. Rapports et Communications. Paris: Masson et Cie. Éditeurs, 1906.

CORNET, P. Rôle et mode de nomination des médecins inspecteurs des écoles. In: LIGUE DES MÉDECINS ET DES FAMILLES. Deuxième Congrès d'Hygiène Scolaire et de Pédagogie Physiologique, Paris, 1905. Rapports et Communications. Paris: Masson et Cie. Éditeurs, 1906.

DINET, R. Le dossier sanitaire de l'écolier, base nécessaire de la pédagogie experimentale et du perfeccionnement individuel. In: LIGUE DES MÉDECINS ET DES FAMILLES. Deuxième Congrès d'Hygiène Scolaire et de Pédagogie Physiologique, Paris, 1905. Rapports et Communications. Paris: Masson et Cie. Éditeurs, 1906.

GOURICHON, H. Hygiène de l'enfant à l'école. In: LIGUE DES MÉDECINS ET DES FAMILLES. Deuxième Congrès d'Hygiène Scolaire et de Pédagogie Physiologique, Paris, 1905. Rapports et Communications. Paris: Masson et Cie. Éditeurs, 1906.

JATOBÁ, C. M. R. Às sombras das escalas: um estudo sobre a concepscão de anormalidade em Alfred Binet. São Paulo, 2002. Tese (Doutorado em Educação) - Faculdade de Educação, Universidade de São Paulo, 2002.

KUHLMANN JR., M. O Congresso Internacional do Ensino (Bruxelas, 1880). A maçonaria e as propostas para a educação das crianças. Anais do VIII Congreso Iberoamericano de Historia de la Educación Latinoamericana, Buenos Aires, 2007.

KUHLMANN JR., M. Notas sobre o Congresso Internacional do Ensino, Bruxelas, 1880. História da Educação, ASPHE, Pelotas, n. 18, p. 59-69, set. 2005.

LAVISSE, E. Allocution de Ernest Lavisse. In: LIGUE DES MÉDECINS ET DES FAMILLES. Deuxième Congrès d'Hygiène Scolaire et de Pédagogie Physiologique, Paris, 1905. Rapports et Communications. Paris: Masson et Cie. Éditeurs, 1906.

LIGUE DES MÉDECINS ET DES FAMILLES. Deuxième Congrès d'Hygiène Scolaire et de Pédagogie Physiologique, Paris, 1905. Rapports et Communications. Paris: 
Masson et Cie. Éditeurs, 1906.

MARTÍNEZ, P. L. M. The hygienist movement and the modernization of education in Spain. Paedagogica Historica, v. 42, n. 16, p. 793-815, dec. 2006.

MATHIEU, A. Allocution de Albert Mathieu. In: LIGUE DES MÉDECINS ET DES FAMILLES. Deuxième Congrès d'Hygiène Scolaire et de Pédagogie Physiologique, Paris, 1905. Rapports et Communications. Paris: Masson et Cie. Éditeurs, 1906.

MÉRY, H. Inspection médicale des écoles primaires, son fonctinnement, recrutement des médecins inspecteurs des écoles. In: LIGUE DES MÉDECINS ET DES FAMILLES. Deuxième Congrès d'Hygiène Scolaire et de Pédagogie Physiologique, Paris, 1905. Rapports et Communications. Paris: Masson et Cie. Éditeurs, 1906.

PARVE, U. Allocution de Unia Stein Parve. In: LIGUE DES MÉDECINS ET DES FAMILLES. Deuxième Congrès d'Hygiène Scolaire et de Pédagogie Physiologique, Paris, 1905. Rapports et Communications. Paris: Masson et Cie. Éditeurs, 1906.

ROUX, C. Le livret scolaire de santé. In: LIGUE DES MÉDECINS ET DES FAMILLES. Deuxième Congrès d'Hygiène Scolaire et de Pédagogie Physiologique, Paris, 1905. Rapports et Communications. Paris: Masson et Cie. Éditeurs, 1906.

TEISSIER. Le livret sanitaire à l'école. In: LIGUE DES MÉDECINS ETT DES FAMILLES. Deuxième Congrès d'Hygiène Scolaire et de Pédagogie Physiologique, Paris, 1905. Rapports et Communications. Paris: Masson et Cie. Éditeurs, 1906.

VIÑAO FRAGO, A. Higiene, salud y educación en su perspectiva histórica. Areas. Revista de Ciencias Sociales, Murcia (Espanha), n. 20, p. 9-24, 2000.

VIÑAO FRAGO, A.; MARTÍNEZ, P. L. M. Introdución. Areas. Revista de Ciencias Sociales, Murcia (Espanha), n. 20, p. 7, 2000.

\section{Notas}

1 A autora ressalta, ainda, que a atuação dessas entidades incluiu a criação de publicações periódicas e o estabelecimento de cátedras nas faculdades de medicina, escolas normais e outras instituições de ensino superior, iniciativas que respondiam aos propósitos de consolidação do campo da higiene escolar.

2 Entre as autoridades francesas presentes na solenidade, destacam-se: J. Gautier, inspetor geral, chefe de gabinete do Ministério de Instrução Pública; Mmme. Kergomard, inspetora geral das escolas maternais; Bonnarie, inspetor da Academia; Marchand, secretário do Conselho Municipal de Paris; Maurice Muret, vice-presidente do Círculo de Paris e representante do conselho geral da Ligue d'Enseignement; L. Gourrichon e Butte, os quais representavam a Sociedade dos Médicos-Inspetores da Cidade de Paris. O evento contou também com a adesão das seguintes entidades francesas: Liga Girondina de Educação Física, Sociedade de Preservação Antituberculose, Sociedade Amiga dos Antigos Alunos de Saint Cloud, Sociedade Amiga dos Professores e Professoras Primárias de Seine e Sociedade Odontológica da França.

3 Enviaram representantes as seguintes entidades estrangeiras: Sociedade Suíça de Higiene Escolar, Sociedade Holandesa para a Simplificação e Aprimoramento dos Exames e dos Programas, Gota de Água e União dos Trabalhadores de Barcelona, Sociedade Inglesa de Dentistas Escolares. Além dessas entidades, participaram do evento representantes da 
Alemanha, da Bélgica, da Holanda, de Portugal e do Brasil, entre outros países.

4 O I Congresso de Higiene Escolar e Pedagogia Fisiológica foi realizado em Paris, em novembro de 1903. Três meses antes desse evento, realizara-se, em Bruxelas, o Congresso de Higiene, que contou com a participação de Mosny, como delegado da França, o qual proferiu uma conferência sobre a temática da higiene escolar. Em 1904, Nuremberg sediou o I Congresso Internacional de Higiene Escolar, que contou com mais de 1.200 participantes. A agenda deste último evento previa a realização da sua segunda edição em Londres, em 1907, e a terceira, em Paris, em 1910. Nesse sentido, o congresso realizado em Paris, em 1905, pela Liga dos Médicos e das Famílias para a Higiene Escolar, foi pensado como parte dos preparativos do congresso que se realizaria em Londres dali a dois anos.

5 O congresso contou com a participação de 91 médicos, 22 professores e apenas 12 pais. Cabe destacar que, se o número de médicos cresceu, da primeira edição do congresso para a segunda, de 65 para 91 e o de professores, de 21 para 22, o número de pais caiu de 14 para 12 .

$6 \mathrm{O}$ formato do congresso, sugerido pela organização dada às atas, indica que, entre as 30 comunicações apresentadas, algumas foram reunidas em sessões que abordavam uma temática comum, as quais eram acompanhadas da discussão dos aspectos abordados pelos autores. Tanto nesse caso quanto no das comunicações que versavam sobre temáticas diversificadas, a apresentação era seguida da leitura, da discussão e da aprovação das conclusões. Organizadas em sessões temáticas, destacam-se as comunicações sobre a educação das famílias, o período destinado às férias escolares, a inspeção médica das escolas e as fichas e cadernetas sanitárias.

7 Segundo Bañuelos (2000), o congresso de 1903 constituiu-se em um momento decisivo no sentido de dirimir um conflito de competências entre diferentes profissionais em relação a um serviço público: a inspeção médica das escolas. As intervenções dos médicos naquele evento são significativas, como procura demonstrar a autora, para evidenciar as resistências e demarcar a necessidade de cautelosa negociação no estabelecimento do caráter confidencial das fichas dos alunos. A relevância dessas questões pode ser verificada quando se observa a recorrência dos temas e do tratamento a eles conferido no segundo congresso.

8 No que se referia à implementação dessas medidas, o autor assinalava os progressos consideráveis alcançados pela Alemanha, pela Suíça, Hungria e pela Bélgica, os quais contrastavam com as incipientes experiências francesas.

9 Curiosamente, no I Congresso de Higiene Escolar e Pedagogia Fisiológica, realizado em 1903, Méry, alegando "desconhecimento pedagógico", defendeu que a atuação da inspeção médica das escolas deveria se restringir a questões estritamente médicas. A posição de Méry contrastava com a de Le Gendre, que postulou, nesse mesmo fórum, a intervenção dos médicos no tratamento de questões pedagógicas, a qual se justificava em função da suposta ignorância dos educadores quanto à "fisiología de los caracteres y la hygiene del trabajo intelectual" (BAÑULOS, 2000).

10 Referindo-se à experiência alemã, Méry oferece elementos para a compreensão da distinção que se procurava estabelecer, naquele momento, entre classes especiais e classes 
auxiliares como espaços de escolarização das crianças que não se adaptavam aos padrões da escola regular: "ao lado das classes auxiliares para as crianças anormais verdadeiramente retardadas, convém assinalar o interesse de se organizar as classes especiais para as crianças cuja inteligência não está diminuída, mas que têm uma tara nervosa, histeria, neurastenia, instabilidade de atenção, como o que vem sendo feito em Manheim nas classes ditas de adiantamento" (MÉRY, 1906, p. 96).

11 Entre essas experiências, Pinard instituíra uma ficha sanitária em escolas de Creusot, cujos dados permitiam, a par da discussão entre o médico e o professor, proceder à seleção física e intelectual dos alunos, por meio das quais se definia, entre outros aspectos, sua progressão no ensino. Butte também adotara um dossiê sanitário bastante detalhado, em uma escola de meninas, resultando do seu trabalho de dois anos a identificação de crianças com problemas de visão e audição e de casos de tuberculose, acompanhados das devidas providências. Segundo Butte, as experiências que conduzira, utilizando um modelo de dossiê que contemplava o registro de um conjunto de informações fornecidas pela família, permitiam desmentir a ideia de que os pais eram hostis à adoção de um instrumento dessa natureza. Conforme destacava, das 60 fichas encaminhadas aos pais, em que se solicitavam dados como nome, sobrenome, local e data de nascimento da criança, modo de aleitamento, datas e resultados da vacinação e revacinações, idade da fala e da marcha, doenças anteriores, estado de saúde dos familiares, apenas uma família havia devolvido a ficha com respostas que lhe pareceram um tanto irônicas, o que o autorizava a concluir que as famílias reconheciam a utilidade desses procedimentos.

12 Quanto à discussão sobre a ficha individual, o autor destaca as posições defendidas por Le Gendre e Letulle, no I Congresso de Higiene Escolar, Rabier, no Congresso do Ensino Secundário, bem como as questões tratadas por Mosny, nas reuniões da liga. Os trabalhos apresentados nos congressos se debruçam sobre a necessidade de instituição de uma caderneta sanitária individual, obrigatória para todas as crianças em idade escolar, como meio de profilaxia das doenças escolares. Já as discussões que têm lugar no âmbito da liga incidem sobre um duplo aspecto, realçando, por um lado, a questão da prevenção de quadros mórbidos e, por outro, o problema da divisão do tempo escolar e dos programas de ensino.

Recebido: 27/10/2009

Aprovado: 25/11/2009

Contato:

Universidade Estadual de Campinas

Faculdade de Educação

Departamento de Educação Conhecimento Linguagem e Arte

Rua Bertrand Russell, 801

Cidade Universitária

CEP 13083-865

Campinas/SP 